\title{
THE EFFECT OF COVID-19 PANDEMIC ON TRAINING \& DEVELOPMENT ACTIVITIES AND PERFORMANCE MANAGEMENT SYSTEMS IN CENTRAL BANKS
}

DOI: 10.17261/Pressacademia.2021.1467

RJBM- V.8-ISS.3-2021(4)-p.260-270

Dogan Basar

Central Bank of the Republic of Turkey, Ankara, Turkey. doganbasar@gmail.com, ORCID: 0000-0002-7570-7444

\begin{tabular}{|c|c|}
\hline Date Received: September 2, 2021 & OPEn OPaCcEss (cc)BY \\
\hline \multicolumn{2}{|l|}{ To cite this document } \\
\hline \multicolumn{2}{|c|}{$\begin{array}{l}\text { Basar, D., (2021). The Effect of COVID-19 pandemic on training \& development activities and performance management systems in central } \\
\text { banks. Research Journal of Business and Management (RJBM), } 8(3), p .\end{array}$} \\
\hline $\begin{array}{l}\text { Permanent link to this document: } h \mathrm{ttp}: / / \text { doi.org/10.17261/Pressacademia.2021.1467 } \\
\text { Copyright: Published by PressAcademia and limited licensed re-use rights only. }\end{array}$ & \\
\hline
\end{tabular}

\section{ABSTRACT}

Purpose- To examine different implementations of training \& development activities and performance management systems in different central banks around the world during COVID-19 pandemic

Methodology- In this research, interview methodology was used. Questionnaires were sent to Federal Reserve Bank, European Central Bank, Bank of France, Bank of England, Bank of Japan, Bank Negara Malaysia, and Bank of Russia. The answers given by central banks were analyzed. Findings- In general, face-to-face training programs were cancelled and e-learning solutions were provided for employees. Training programs to inform about pandemic and seminars about remote working conditions were organized. There has been no big change in performance management systems.

Conclusion- With the restrictions of COVID-19 pandemic, traditional training programs has transferred to the digital platforms to avoid physical interaction. Performance management activities has basically remained same during the pandemic.

Keywords: Human resources management, training and development, performance management, COVID-19, central banking JEL Codes: J24, M53, 015

\section{COVID-19 PANDEMISININ DÜNYA MERKEZ BANKALARININ EĞiTiM VE GELIŞiM FAALIYETLERi iLE PERFORMANS SÜREÇLERI ÜZERINE ETKISI}

\section{ÖZET}

Amaç- Dünyanın farklı ülkelerindeki Merkez Bankalarının, COVID-19 pandemi sürecinde eğitim ve gelişim faaliyetleri ile performans yönetim sistemlerini nasıl devam ettirdiklerine yönelik durum analizi yapmak ve uygulama örneklerini sunmaktır.

Yöntem- Araştırmada görüşme yöntemi kullanılmıştır. ABD, Almanya, Avrupa, Fransa, Japonya, İngiltere, Malezya ve Rusya Merkez Bankalarına önceden hazırlanan soru setleri gönderilmiştir. Merkez Bankalarının verdiği cevaplar karşılaştıılarak analiz edilmiştir.

Bulgular- Genel olarak yüz yüze eğitimler pandemi koşulları nedeniyle askıya alınmış, bunun yerine çevrimiçi eğitim çözümleri sunulmuştur. Ayrıca, dijital platformlar üzerinden pandemi sürecine özgü farkındalık artıııı eğitim programlarına ve uzaktan çalışmaya yönelik seminerlere de yer verilmiştir. Performans yönetim sistemlerinde ise ciddi bir değişiklik yapılmamıştır.

Sonuç- COVID-19 pandemisiyle birlikte gelen kısıtlamaların fiziksel etkileşim gerektiren uygulamaları dönüştürdüğü, geleneksel eğitim uygulama yöntemlerinin dijital platformlara taşınarak boyut değiştirdiği değerlendirilmektedir. Performans uygulamaları ise temelde değişmeden devam edebilmektedir.

Anahtar Kelimeler: İnsan kaynakları yönetimi, eğitim ve geliştirme, performans yönetimi, COVID-19, merkez bankaları JEL Kodları: J24, M53, 015

\section{GiRiş}

COVID-19 pandemi süreci günümüz çalışma hayatını ve kurumsal süreçleri ciddi sınamalarla karşı karşıya bırakmıştır. Çin'in Wuhan kentinde ortaya çıkarak tüm Dünyaya yayılan koronavirüs salgınıyla birlikte, hem bireyler hem kurumlar bir anda beklenmedik bir kriz yönetimi süreciyle baş etmek zorunda kalmıştır. Sağlıkla ilgili endişelerin en üst düzeyde olduğu pandemi koşullarında, diğer taraftan da üretim, ticaret, ulaşım, dağıtım ve diğer hizmetlerin de aksamadan devam etmesi gerekmiştir. Bu gereklilik, insan kaynağı yönetiminin en etkin ve en verimli şekilde kullanımını kritik bir öneme taşımıştır. 
Kurumlar, insan kaynakları yönetiminin önemli fonksiyonlarından olan eğitim, gelişim ve performans süreçlerini, küresel pandemi koşullarının getirmiş olduğu kısıtlamalar ve dönüşümlerin gölgesinde devam ettirmek zorunda kalmıştır. İş sürekliliği ve yeni koşullara hızlı uyum sağlanması adına bu sürece özel eğitim ve geliştirme faaliyetlerinin çevik bir şekilde uygulamaya konulması gerekmiştir. Çalışan motivasyonun en üst seviyede tutulabilmesi adına performans değerlendirmelerinin de dönemin koşulları göz önünde bulundurularak adil ve şeffaf yöntemlerle gerçekleştirilmesi daha da önem kazanmıştır.

Merkez Bankaları da bu süreçten hem ana görevlerine yönelik iş süreçleri hem de insan kaynakları süreçleri noktasında kaçınılmaz olarak etkilenmiştir. Ülkelerin finansal istikrarını korumasında bel kemiği görevini üstlenen Merkez Bankalarının, çalışanlarının eğitim ve gelişim faaliyetlerinin aksamadan devam etmesi, diğer kurumlarda olduğu gibi Merkez Bankalarının nihai başarısı açısından da önemli bir gereksinim olmuştur. Dünyanın farklı yerlerinde bulundukları ülkelerde kendilerine has süreçlere sahip olan Merkez Bankalarında bu süreçte ortaya çıkan uygulama örneklerinin paylaşılmasının, alana katkısı noktasında faydalı olduğu değerlendirilmektedir.

Bu çalışma kapsamında, Dünyanın gelişmiş ve gelişmekte olan ülkelerindeki Merkez Bankalarına, COVID-19 pandemi sürecinde eğitim ve gelişim faaliyetleri ile performans yönetim sistemi uygulamaları kapsamında nası bir yol izledikleri, ne gibi önlemler aldıkları, ne tür yenilikler getirdikleri ve pandemi süreci sonrası hakkındaki öngörüleri hakkında soru setleri iletilmiştir. Soru setleri gönderilen ABD, Almanya, Avrupa, Fransa, Japonya, İngiltere, Malezya ve Rusya Merkez Bankalarının verdikleri cevaplar doğrultusunda mevcut durum değerlendirilmesi yapılmış, pandemi dönemi sırası ve sonrası için öneriler sıralanmıştır. Çalışma sonuçlarının ve önerilerin pandemi süreci ve sonrasında kurumların insan kaynakları uygulamalarında yol gösterici olması beklenmektedir.

COVID-19 pandemi sürecinin farklı ülkelerin merkez bankalarının eğitim ve gelişim faaliyetleri ile performans süreçleri üzerine etkisini inceleyen bu çalışmanın "Literatür İncelemesi" bölümünde, insan kaynakları yönetiminde eğitim ve gelişim faaliyetleriyle performans uygulamalarının yeri ve önemi kavramsal olarak ele alınmıştır. COVID-19 pandemisinin insan kaynakları uygulamaları ve Merkez Bankaları üzerindeki etkilerine literatür incelemesi kapsamında değinilmiştir. "Veri ve Yöntem" bölümünde, araştırmanın örneklemi, soru setleri, veri toplanması süreci ve veri analizine yönelik bilgiler verilmiştir. "Bulgular ve Tartışma" bölümünde, örneklemi oluşturan Merkez Bankalarının verdikleri cevaplar çerçevesinde araştırma bulguları karşılaştırmalı olarak açıklanmıştır. "Sonuç ve Değerlendirme" bölümünde ise, araştırma sonuçları değerlendirilmiştir.

\section{LITERATÜR INCELEMESI}

\section{2. İnsan Kaynakları Yönetiminde Eğitim ve Gelişim Faaliyetleri}

Eğitim ve gelişim faaliyetleri insan kaynakları yönetiminin kritik ve olmazsa olmaz fonksiyonlarından biri olarak kabul edilmektedir (Barutçugil, 2002). Çalışanların bilgi ve beceri seviyelerinin artırılması, mevcut yetkinliklerinin geliştirilmesi ve performanslarının iyileştirilmesi amacıyla yapılan planlı çalışmalar bütünü (Olaniyan ve Ojo, 2008) olarak tanımlanabilen eğitim ve gelişim faaliyetleri, sadece bireysel olarak çalışanların değil örgütün gelişimini de desteklemektedir. Çalışanlarının eğitimine gereken önemi vermeyen örgütlerin uzun vadede başarılı olmaları mümkün görünmemektedir.

İçinde bulunduğumuz bilgi çağında değişim, gelişim ve adaptasyon yeteneği hayati önem taşımakta olup, sadece çalışanların değil aynı zamanda örgütlerin de sürekli öğrenen ve gelişen bir yapıda olması gerekmektedir. Bu gereklilik "öğrenen organizasyon" terimiyle literatürde sıklıkla vurgulanmaktadır (Armstrong ve Foley, 2003; Edmondson ve Moingeon, 1998; Garvin, Edmondson ve Gino, 2008; Mills ve Friesen, 1992). Öğrenen organizasyon, çalışanlarının eğitimini destekleyerek sürekli gelişime ve değişime açık olan; çalışanlarıyla birlikte öğrenen, gelişen ve değişen; çalışanlarının bilgiyi oluşturduğu, paylaştığı ve bunu kurumsal bilgiye dönüştürdügü örgüt yapısını ifade etmektedir (Bui, 2019; Edmondson ve Moingeon, 1998; Yang, Watkins ve Marsick, 2004). Böylelikle, çalışanlarının mevcut bilgi, beceri ve yetkinliklerini kurumsal olarak beklenen seviyeye çıkarmayı hedefleyen örgütler, eğitim ve gelişim faaliyetlerini etkin bir şekilde kullanarak sürekli daha iyiye doğru gelişmeyi sağlayabilmektedir.

Örgütlerde eğitim süreçleri genel olarak ihtiyaç analizi, tasarım, geliştirme, uygulama ve değerlendirme adımlarından oluşmaktadır (Barutçugil, 2002; Tannenbaum ve Yukl, 1992). Eğitim ihtiyaç analiziyle örgütün gereksinimlerinin yanında çalışanların mesleki teknik ve davranışsal gelişim ihtiyaçlarının belirlenmesi hedeflenmektedir. Eğitim ihtiyacı belirlendikten sonra tasarım aşamasında içerik, yöntem, eğitmen, zaman, maliyet, değerlendirme boyutları göz önüne alınarak eğitim programı planlanmaktadır. Geliştirme adımında eğitim içeriği, belirlenen yöntem ve süreye göre hazırlanmaktadır. Uygulama adımında ise planlanan ve geliştirilen eğitim programı uygulamaya alınmaktadır. Son olarak, değerlendirme aşamasında katılımcıların tepkisi, öğrenme düzeyi, davranış değişimi ve örgüte olan katkının ölçülmesi hedeflenmektedir.

Eğitim ve gelişim faaliyetlerinin, değişen ihtiyaçlara uyum sağlayabilmesi ve her koşulda çalışanların gelişimini destekleyebilmesi motivasyon, performans, verimlilik ve örgütsel bağılık açısından önemli bir yere sahiptir (Bulut ve Culha, 2010; Olaniyan ve Ojo, 2008). Bu nedenle, farklı koşul ve sınamalar karşısında da örgütlerin çevik bir yaklaşım sergileyerek eğitim ve gelişim faaliyetlerini devam ettirmesi beklenmektedir. 


\subsection{Insan Kaynakları Yönetiminde Performans Yönetim Sistemleri}

Performans yönetim sistemi, organizasyonun amaç, vizyon ve hedefleri doğrultusunda çalışanların performansını yönetmeyi hedefleyen sistematik bir yaklaşımı ifade etmektedir (Bretz, Milkovich ve Read, 1992; Davies, 1999; Fletcher ve Perry, 2001). Çalışanın performans değerlendirmesi; organizasyonel planlama, işe alım, yetenek yönetimi, eğitim ve gelişim, ücret yönetimi gibi farklı insan kaynakları süreçlerinden beslenmekte ve bu süreçlere girdi sunmaktadır.

Etkili bir performans yönetim süreci sadece çalışanın mevcut performansının değerlendirilmesi ve bu düzeyin geliştirilmesini değil aynı zamanda örgütsel verimliliğin artırılmasını da kapsamaktadır (Martin ve Bartol, 1998). Performans yönetim sistemi, çalışanların eğitim eksikliklerinin belirlenmesi, kariyer yönetimi ve yedeklemenin yapılması, verimliliğin artırılması için organizasyonel düzenlemelerin yapılması ve kurum içi iletişimin güçlenmesine katkı sağlayarak örgütün stratejik hedeflerine ulaşmasında önemli bir yere sahiptir.

Performans yönetim süreci “planlama”, "izleme”, “gözden geçirme” ve “ödüllendirme” adımlarını içeren döngüsel ve bütünsel bir yaklaşımı içinde barındırmaktadır (Hartle, 1995). Planlama aşamasında çalışandan beklenen kişisel ve kurumsal performans hedefleri örgütün stratejik hedefleri doğrultusunda belirlenmektedir. İzleme aşamasında çalışanın performans hedeflerine ulaşmadaki ilerlemesi takip edilmekte, revize edilmesi gereken noktalar varsa yeniden ele alınmaktadır. Gözden geçirme aşamasında bir performans dönemi boyunca çalışanın göstermiş olduğu ilerleme ve gelişim değerlendirilmekte, geri bildirim verilmektedir. Son olarak, ödüllendirme aşamasında çalışanın motivasyonunu artıracak ve sonraki performans dönemi için gelişimini sürdürecek ödüller verilebilmekte, teşvik uygulamaları hayata geçirilebilmektedir.

Performans yönetim sisteminde süreçlerin etkin ve etkili bir şekilde yürütülmesi çalışan motivasyonu, gelişimi ve nihai olarak da örgütsel verimlilik için önemlilik arz etmektedir (Davies, 1999). Performans yönetim süreçleri genel olarak benzer olmakla birlikte her örgütün kendi yapısı ve dinamikleri çerçevesinde özelleşebilmektedir.

\subsection{COVID-19 Pandemi Sürecinin Eğitim ve Gelişim Faaliyetleri ile Performans Uygulamalarına Etkileri}

Tüm dünyayı etkisi altına alan küresel COVID-19 salgınının, hayatın tüm alanlarında olduğu gibi insan kaynakları süreç ve uygulamalarına da yansımaları olmuştur (Akkermans, Richardson ve Kraimer, 2020; Carnevale ve Hatak, 2020; Kniffin ve diğerleri, 2021). Genel olarak "çalışıyorsa hiç kurcalama" eğilimine sahip olan ve değişime mesafeli yaklaşan kurumlar bile pandemi döneminde kurumsal süreçlerinde ve insan kaynakları uygulamalarında değişime gitmek mecburiyetinde kalmıştır (Serifsoy ve Teker, 2020). Sektörlerin büyük bir çoğunluğunda çalışanlar faaliyetlerini zorunlu olarak evden yürütmüş, çok sayıda işyerinde dönüşümlü veya esnek çalışma modellerine geçilmiştir. Fiziksel ortamlarda ve etkileşimli olarak geçekleştirilen çok sayıda uygulama dijital platformlara taşınmıştır. Ulusal ve uluslararası düzeyde getirilen kısıtlamalar olağan iş süreçlerinde boyut değişimine neden olmuştur. Bu noktada, Kurumların çalışanlarının eğitimi ve gelişimi ile performanslarının ölçüm ve değerlendirilmesine yönelik faaliyetlerini pandemi koşullarına uyarlaması gerekmiştir (Carnevale ve Hatak, 2020).

Fiziksel etkileşim içeren etkinlik, toplantı ve eğitimlerin askıya alınması, yüz yüze gerçekleştirilmesi mecburi faaliyetlerin ise maske, mesafe, koruyucu donanım kullanımı gibi hijyen kuralları dikkate alınarak kısıtlı koşullarda gerçekleştirme zorunluluğu dijital öğrenme araçlarının doğru ve etkili bir şekilde kullanıımasının önemini artırmıştır (Bozkurt, 2020; Tuna ve Çelen, 2020). Beklemedikleri bir şekilde evden çalışma düzenine geçen çalışanların hem yeni çalışma düzenine alışması hem de bireysel gelişimlerini devam ettirmesi gerekliliği kurumlarda eğitim birimlerinin sorumluklarını da artırmıştır. Özellikle ilk ve orta kademe yönetici pozisyonundaki çalışanlara yönelik uzaktan ekip yönetimi, motivasyonu koruma, süreç ve kriz yönetimi, koçluk ve mentörlük uygulamaları gibi konularda yetkinlik geliştirme ve destekleme programlarına ihtiyaç duyulmuştur (Vnoučková, 2020).

Her ne kadar son yıllarda dijital öğrenme çözümleri yaygınlaşmaya başlamış olsa da pandemiden önce kurumların çoğunlukla geleneksel öğrenme ortamlarını tercih ettikleri görülmekteydi. Bu noktada, COVID-19 pandemi sürecinde çevrimiçi öğrenme ortamlarını tercih etme zorunluğu kurumsal eğitim faaliyetlerinde dönüşümü de beraberinde getirmiştir (Bozkurt, 2020; Zhao, 2020). Dijital öğrenme ortamlarına hızlı bir şekilde uyum sağlayabilen kurum ve çalışanlar eğitim ve gelişim faaliyetlerini ciddi bir kayba uğramadan sürdürebilmiştir. Diğer taraftan, süreçlerin tamamıyla dijital ortamlara taşınması bilgi güvenliği ve siber güvenlikle ilgili riskleri daha ciddi bir boyuta taşımıştır (Groenendaal ve Helsloot, 2021; Herath ve Herath, 2020).

COVID-19 pandemi döneminden ciddi seviyede etkilenen işe alım srüeçleri ile eğitim ve geliştirme faaliyetlerinin aksine performans uygulamalarının pandemi koşullarından nispeten daha az etkilendiği görülmüştür. Kurumların performans yönetim sistemlerinde büyük değişikliklere gitmedikleri, bunun yerine performans hedeflerini revize ederek pandemi koşulları çerçevesinde çalışanlarına esneklik sağladıkları belirtilmiştir (Aguinis ve Burgi-Tian, 2021; Tuna ve Çelen, 2020). Performans uygulamalarını temel olarak çalışanların iş yüklerinin takip edilmesi ve izlenmesi seviyesinde tutan kurumlar, performans değerlendirme sistemlerinde yer alan ödül ve terfi mekanizmalarını askıya almış ya da ertelemiştir (Nutsubidze ve Schmidt, 2021). 


\subsection{COVID-19 Pandemi Sürecinde Merkez Bankaları}

Merkez Bankalarının bulundukları ülkelerde para politikasının yönetilmesi, finansal istikranın ve fiyat istikrarının sağlanması, finans kurumları ve piyasalarla ilgili düzenleyici önlemler alınması gibi temel görevleri bulunmaktadır (Türkiye Cumhuriyet Merkez Bankası, 2018). COVID-19 pandemi sürecinin ülke ekonomilerini de ciddi anlamda etkisi altına almasıyla birlikte, Merkez Bankalarının görevlerini en az pandemi öncesindeki kadar etkili sürdürmesinin önemi de atmıştır.

Öte yandan, tüm sektörlerde olduğu gibi Merkez Bankası çalışanları da pandemi koşullarından kaçınılmaz olarak etkilenmiştir. Kurumların başarısında insan kaynakları yönetiminin önemi göz önünde bulundurulduğunda (Bingöl, 2003; Kirilmaz, 2020; Olaniyan ve Ojo, 2008), pandemi sürecinde çalışanlarının gelişimine yönelik eğitim faaliyetlerinin ve performans yönetimi uygulamalarının yeniden değerlendirilmesi ve değişikliklere hızlıca adapte edilmesi önem kazanmıştır (Carnevale ve Hatak, 2020).

Buna rağmen, her ülkede tek olan ve kendine özgü süreçlere sahip Merkez Bankalarında insan kaynakları yönetimiyle ilgili literatürde yeterli sayıda ve güncel çalışmanın yer almadığı görülmüştür. Hem bulundukları ülke ekonomileri hem de küresel ölçekte Dünya ekonomisi üzerinde önemli rollere sahip Merkez Bankalarının yönetimsel ve insan kaynağı açısında da incelenmesinin alana önemli katkılar sağlayabileceği değerlendirilmektedir.

\section{VERI VE YÖNTEM}

Bu çalışmada nitel araştırma yöntemlerinden olan görüşme yöntemi kullanılmıştır. Pandemi koşulları ve kısıtlamalar dolayısıyla görüşme soruları dijital ortamda iletilmiştir. Çalışmada, örneklem olarak belirlenen sekiz yabancı Merkez Bankasına soru setleri gönderilmiş, gelen cevaplar veri seti olarak kullanılmıştır.

Eğitim ve gelişim faaliyetleriyle ilgili soru setinde;

- COVID-19 döneminde eğitim ve gelişim faaliyetlerinin nasıl devam ettiği,

- Yüz yüze yapılan eğitim programlarında alınan önlemler,

- Çevrimiçi eğitim çözümleri,

- Çalışanların pandemi döneminde düzenlenen eğitim faaliyetlerine karşı tutumu,

- Pandemi süreciyle birlikte eğitim ve gelişim faaliyetlerinde yapılan değişiklikler,

- Pandemi döneminde eğitim ve gelişim faaliyetlerinde yaşanan zorluklar ve riskler hakkında sorular yer almıştır.

Performans yönetim sistemleriyle ilgili soru setinde ise;

- Merkez bankalarının mevcut performans uygulamaları,

- COVID-19 pandemi koşullarının performans değerlendirme süreçlerine etkisi,

- Ödül ve ceza uygulamaları ile COVID-19 pandemi sürecine özel düzenlemeler hakkında sorular yer almıştır.

Son olarak, Türkiye Cumhuriyet Merkez Bankası'nda sürdürülen eğitim ve gelişim faaliyetleri ile performans yönetimi uygulamaları COVID-19 pandemi süreci göz önünde bulundurularak değerlendirilmiştir. Ülkemiz uygulamaları ile yabancı Merkez Bankalarındaki uygulamalar karşılaştırılmıştır.

\section{BULGULAR VE TARTIŞMA}

\subsection{COVID-19 Pandemi Sürecinde Yabancı Merkez Bankalarında Eğitim ve Gelişim Faaliyetleri}

Salgın döneminde eğitim ve gelişim uygulamaları kapsamında ne tür önlemler aldıkları, ne gibi yenilikler uyguladıkları ve çalışanların eğitimlerine yönelik yürüttükleri faaliyetler hakkında fikir alışverişinde bulunmak üzere ABD, Almanya, Avrupa, Fransa, İngiltere, Japonya, Malezya ve Rusya Merkez Bankalarıyla iletişime geçilmiştir. Belirtilen bankalarının cevapları ve söz konusu olağanüstü dönemdeki eğitim ve gelişim faaliyetleri Tablo 1'de yer almaktadır.

Tablo 1: COVID-19 Döneminde Dünya Merkez Bankalarında Eğitim ve Gelişim Faaliyetlerinin Karşılaştırılması

\begin{tabular}{|c|c|c|c|c|c|c|}
\hline Merkez Bankası & $\begin{array}{l}\text { Pandemi } \\
\text { sürecinde yüz } \\
\text { yüze eğitimler }\end{array}$ & $\begin{array}{l}\text { Çevrimiçi } \\
\text { eğitim } \\
\text { çözümleri }\end{array}$ & $\begin{array}{l}\text { Kullanılan } \\
\text { çevrimiçi } \\
\text { platformlar }\end{array}$ & $\begin{array}{l}\text { Çalışanların } \\
\text { çevrimiçi } \\
\text { eğitimlere karşı } \\
\text { tutumları }\end{array}$ & $\begin{array}{l}\text { Pandemi } \\
\text { dönemine özel } \\
\text { eğitim } \\
\text { uygulamaları }\end{array}$ & $\begin{array}{l}\text { Pandemi } \\
\text { döneminde eğitim } \\
\text { programlarında } \\
\text { karşılaşılan zorluk } \\
\text { ve sınamalar }\end{array}$ \\
\hline $\begin{array}{l}\text { Amerika } \\
\text { Merkez Bankası } \\
\text { (Federal } \\
\text { Reserve Bank) }\end{array}$ & $\begin{array}{l}\text { Tamamı askıya } \\
\text { alınmıştır }\end{array}$ & $\begin{array}{l}\text { Sanal sınıf } \\
\text { eğitimleri, } \\
\text { çevrimiçi } \\
\text { seminerler }\end{array}$ & $\begin{array}{l}\text { Cisco } \\
\text { Webex } \\
\text { Zoom }\end{array}$ & $\begin{array}{l}\text { Başlangıçta uyum } \\
\text { sorunları yaşansa } \\
\text { da genel olarak } \\
\text { olumlu }\end{array}$ & $\begin{array}{l}\text { "Değişiklik", } \\
\text { "esneklik" ve } \\
\text { "değişim yönetimi" } \\
\text { konularında } \\
\text { çevrimiçi seminer } \\
\text { programları }\end{array}$ & $\begin{array}{l}\text { Zaman kısıtları, } \\
\text { eğitim biriminin iş } \\
\text { yükünün artması, } \\
\text { iş-yaşam } \\
\text { dengesinin } \\
\text { etkilenmesi }\end{array}$ \\
\hline
\end{tabular}




\begin{tabular}{|c|c|c|c|c|c|c|}
\hline $\begin{array}{l}\text { Almanya } \\
\text { Merkez Bankası } \\
\text { (Deutsche } \\
\text { Bundesbank) }\end{array}$ & $\begin{array}{l}\text { Az sayıda } \\
\text { eğitimin hijyen } \\
\text { tedbirleri } \\
\text { çerçevesinde } \\
\text { düzenlenmiştir }\end{array}$ & $\begin{array}{l}\text { Sanal sınıf } \\
\text { eğitimleri, } \\
\text { çevrimiçic } \\
\text { konferanslar, } \\
\text { telefon } \\
\text { koçluğu ve e- } \\
\text { öğrenme } \\
\text { materyalleri }\end{array}$ & $\begin{array}{l}\text { Cisco } \\
\text { Webex }\end{array}$ & $\begin{array}{l}\text { Düzenli katılımın } \\
\text { sağlanmasında } \\
\text { sorunlar yaşansa } \\
\text { da genel olarak } \\
\text { olumlu }\end{array}$ & Belirtilmemiştir & $\begin{array}{l}\text { Yüz yüze } \\
\text { eğitimlerin sanal } \\
\text { ortama } \\
\text { uyarlanmasındaki } \\
\text { zorluklar, teknik } \\
\text { aksaklıklar, eğitim } \\
\text { biriminin iş } \\
\text { yükünün artması }\end{array}$ \\
\hline $\begin{array}{l}\text { Avrupa Merkez } \\
\text { Bankası } \\
\text { (European } \\
\text { Central Bank) }\end{array}$ & $\begin{array}{l}\text { Tamamı askıya } \\
\text { alınmıştır }\end{array}$ & $\begin{array}{l}\text { Sanal sınıf } \\
\text { eğitimleri }\end{array}$ & $\begin{array}{l}\text { Cisco } \\
\text { Webex } \\
\text { Mural }\end{array}$ & Belirtilmemiştir & $\begin{array}{l}\text { Yönetici eğitimleri, } \\
\text { uzaktan çalışmayı } \\
\text { destekleyen } \\
\text { eğitimler }\end{array}$ & $\begin{array}{l}\text { Bağlantı sorunları } \\
\text { ve teknik } \\
\text { aksaklıklar }\end{array}$ \\
\hline $\begin{array}{l}\text { Fransa Merkez } \\
\text { Bankası (Bank } \\
\text { of France) }\end{array}$ & $\begin{array}{l}\text { Tamamı askıya } \\
\text { alınmıştır }\end{array}$ & $\begin{array}{l}\text { Sanal sınıf } \\
\text { eğitimleri, } \\
\text { seminerler } \\
\text { (webinar), } \\
\text { ses yayınları } \\
\text { (podcast) }\end{array}$ & $\begin{array}{l}\text { Cisco } \\
\text { Webex } \\
\text { Skype }\end{array}$ & $\begin{array}{l}\text { Genel olarak } \\
\text { olumlu }\end{array}$ & $\begin{array}{l}\text { Pandemi dönemine } \\
\text { özel olarak farklı } \\
\text { temalarda eğitimler }\end{array}$ & Belirtilmemiştir \\
\hline $\begin{array}{l}\text { İngiltere } \\
\text { Merkez Bankası } \\
\text { (Bank of } \\
\text { England) }\end{array}$ & $\begin{array}{l}\text { Tamamı askıya } \\
\text { alınmıştır }\end{array}$ & $\begin{array}{l}\text { Sanal sınıf } \\
\text { eğitimleri, } \\
\text { e-öğrenme } \\
\text { materyalleri }\end{array}$ & $\begin{array}{l}\text { Avaya } \\
\text { Equinox } \\
\text { Cisco } \\
\text { Webex } \\
\text { MS Teams } \\
\text { Zoom }\end{array}$ & $\begin{array}{l}\text { Genel olarak } \\
\text { olumlu }\end{array}$ & $\begin{array}{l}\text { Uzaktan çalışma, } \\
\text { hibrit toplantılar } \\
\text { gibi konularda } \\
\text { eğitimler, dışardan } \\
\text { alınan platform } \\
\text { üzerinden } \\
\text { özyönetimli } \\
\text { öğrenme }\end{array}$ & $\begin{array}{l}\text { Yüz yüze } \\
\text { eğitimlerin sanal } \\
\text { ortama } \\
\text { uyarlanmasındaki } \\
\text { zorluklar, bilgi } \\
\text { güvenliği } \\
\text { politikasından } \\
\text { kaynaklı kısıtlar }\end{array}$ \\
\hline $\begin{array}{l}\text { Japonya Merkez } \\
\text { Bankası (Bank } \\
\text { of Japan) }\end{array}$ & $\begin{array}{l}\text { Gerekli } \\
\text { önlemler } \\
\text { alınarak sadece } \\
\text { merkez ofis } \\
\text { çalışanları için } \\
\text { devam etmiştir }\end{array}$ & $\begin{array}{l}\text { Sanal sınıf } \\
\text { eğitimleri }\end{array}$ & $\begin{array}{l}\text { Kuruma ait } \\
\text { video } \\
\text { konferans } \\
\text { sistemi }\end{array}$ & $\begin{array}{l}\text { Genel olarak } \\
\text { olumlu }\end{array}$ & $\begin{array}{l}\text { Pandemi } \\
\text { döneminde işe } \\
\text { başlayanlar için } \\
\text { takip programı }\end{array}$ & $\begin{array}{l}\text { Eğitim katılımcıları } \\
\text { arasında } \\
\text { sosyalleşme } \\
\text { imkânının } \\
\text { kısıtlanması }\end{array}$ \\
\hline $\begin{array}{l}\text { Malezya } \\
\text { Merkez Bankası } \\
\text { (Bank Negara } \\
\text { Malaysia) }\end{array}$ & $\begin{array}{l}\text { Az sayıda } \\
\text { eğitimin hijyen } \\
\text { tedbirleri } \\
\text { çerçevesinde } \\
\text { düzenlenmiştir }\end{array}$ & $\begin{array}{l}\text { Sanal sınıf } \\
\text { eğitimleri, } \\
\text { çevrimiçi } \\
\text { seminerler, e- } \\
\text { öğrenme } \\
\text { materyalleri }\end{array}$ & MS Teams & $\begin{array}{l}\text { Çeşitli uyum } \\
\text { sorunları yaşansa } \\
\text { da genel olarak } \\
\text { olumlu }\end{array}$ & $\begin{array}{l}\text { İşbirlikçi öğrenme } \\
\text { (collaborative } \\
\text { learning), } \\
\text { oyunlaştırma } \\
\text { (gamification) vb. } \\
\text { etkileşimi artıran } \\
\text { yöntemler }\end{array}$ & $\begin{array}{l}\text { Yüz yüze } \\
\text { eğitimlerin sanal } \\
\text { ortama } \\
\text { uyarlanmasındaki } \\
\text { zorluklar }\end{array}$ \\
\hline $\begin{array}{l}\text { Rusya Merkez } \\
\text { Bankası (Bank } \\
\text { of Russia) }\end{array}$ & $\begin{array}{l}\text { Tamamı askıya } \\
\text { alınmıştır }\end{array}$ & $\begin{array}{l}\text { Uzaktan } \\
\text { öğrenme } \\
\text { kapsamında } \\
\text { mümkün olan } \\
\text { bütün } \\
\text { formatlar }\end{array}$ & $\begin{array}{l}\text { Webtutor } \\
\text { iMind } \\
\text { MS Teams } \\
\text { Webex }\end{array}$ & $\begin{array}{l}\text { Genel olarak } \\
\text { olumlu }\end{array}$ & $\begin{array}{l}\text { Psikolojik istikrar, } \\
\text { stres yönetimi, } \\
\text { evden çalışma, öz } \\
\text { düzenleme, yabancı } \\
\text { dil eğitimleri }\end{array}$ & $\begin{array}{l}\text { Teknik sorunlar, } \\
\text { bilgi güvenliği } \\
\text { politikasından } \\
\text { kaynaklı kısıtlar }\end{array}$ \\
\hline
\end{tabular}

\section{Amerika Merkez Bankası (Federal Reserve Bank)}

Amerika Merkez Bankasında pandemi sürecinde tüm yüz yüze eğitimlere ara verilmiş; Webex ve Zoom platformları üzerinden sanal sınıf eğitimleri ve çevrimiçi seminerler düzenlenmiştir. Çevrimiçi düzenlen eğitimlere çalışanların çoğunlukla aktif katılım sağladığı fakat evde bakmakla yükümlü oldukları kişiler nedeniyle bazı çalışanların başlangıçta bir alışma sürecinden geçtiği belirtilmiştir. Bu noktada, Banka olarak eğitim tasarımında zaman kısıtlarının, iş-yaşam dengesinin ve eğitim yükünün dikkate alındığı vurgulanmıştır. Pandemi döneminde, mevcut eğitim programlarının kısaltılmış; her ay "değişiklik", "esneklik" ve "değişim yönetimi" konularında çevrimiçi seminer programları gerçekleştirilmiştir.

\section{Almanya Merkez Bankası (Deutsche Bundesbank)}

Almanya Merkez Bankasında, pandemi öncesi döneme göre daha az sayıda yüz yüze eğitimin hijyen tedbirleri göz önünde bulundurarak düzenlendiği belirtilmiştir. Pandemi sürecinde düzenlenen çevrimiçi eğitimlerde ise Webex platformu tercih edilmiş; sanal sınıflar, çevrimiçi konferanslar, telefon koçluğu ve e-öğrenme yöntemleri yüz yüze eğitimlere alternatif olarak kullanılmıştır. Düzenlenen çevrimiçi eğitimlere katılan çalışanların söz konusu eğitimleri olumlu değerlendikleri vurgulanmıştır. Öte yandan, yüz yüze düzenlenen eğitimlerin yaklaşık \%20'sinin sanal ortama taşınmasında zorluk yaşandığı, çevrimiçi eğitimlere düzenli katılımın sağlanamadığı, Webex platformunda teknik aksaklıkların meydana gelebildiği ve eğitim birimi çalışanlarının çalışma yüklerinin arttığı da ifade edilmiştir. Pandeminin ilk zamanlarında ertelenen zorunlu programların, ilerleyen süreçte daha az sayıda katılımla yürütülmeye başlandığı belirtilmiştir. 


\section{Avrupa Merkez Bankası (European Central Bank)}

Avrupa Merkez Bankası, pandemi sürecinde tüm yüz yüze eğitimlerin iptal edilerek gerekli eğitimlerin çevrimiçi düzenlendiğini belirtmiştir. Çevrimiçi eğitimler kapsamında, temel olarak Webex platformunun kullanılmasının istendiği fakat Mural gibi platformların kullanımının da kabul edildiği ifade edilmiştir. Eğitimler planlanırken sanal ortama uyum sağlayacak değişiklikler (Örneğin, 1 günlük sınıf eğitimlerinin iki yarım günlük oturumlar şeklinde planlanması vb.) yapıldığı iletilmiştir. Uzaktan eğitimlerde, internet bağlantı kalitesi nedeniyle başlangıçta bazı problemlerle karşılaşılsa da zaman içerisinde bu problemlerin sayısı azalmıştır. Eğitimler esnasında eğitmenlere gerekli teknik desteğin sağlandığı vurgulanmıştır. Pandemi sürecinde eğitim programları arasında önceliklendirme yapılmamış, bunun yerine mümkün olduğunca uzaktan eğitime geçiş yapılmaya çalışılmıştır. Ayrıca, bu dönemde yöneticilere yönelik olarak ekiplerini uzaktan yönetmelerini destekleyecek eğitim programlarının gerçekleştirileceği; uzaktan çalışmayı destekleyen farklı eğitimlerin geliştirilmesine yönelik çalışmaların da devam ettiği ifade edilmiştir.

\section{Fransa Merkez Bankası (Bank of France)}

Fransa Merkez Bankası, pandemi sürecinde yüz yüze eğitimlerin tamamını askıya aldığını belirtmiştir. Zorunlu olarak düzenlenmesi gereken yüz yüze eğitimlerde maske takma zorunluğu ve sosyal mesafe kurallarının uygulandığı ifade edilmiştir. Bazı şube çalışanlarının yüz yüze eğitimler için Paris'in dışında yer alan Bankanın eğitim merkezine seyahat etme noktasında isteksiz olduğu görülmüştür. Çevrimiçi eğitimler kapsamında, Skype ve Webex platformları üzerinden sanal sınıflar, seminerler (webinar) ve ses yayınları (podcast) gerçekleştirilmiştir. Uzaktan çalışma döneminde, kurallar, işi organize etme, riskleri önleme gibi konuları içeren "kriz döneminde uzaktan yönetim" adında özel bir eğitim programı hazırlanmıştır. Bu eğitimi takip eden yöneticilerden çok olumlu dönüşler alındığı ifade edilmiştir. Ayrıca, pandemi dönemine özel olarak farklı temalarda ("COVID-19 ile ilgili temel bilgiler", "kendini ve diğerlerini koruma", "ofiste doğru refleksler", "semptomlar veya pozitif vaka durumunda tepki verme" vb. konu başlıklarını içeren) eğitimler sunulmuştur.

\section{İngiltere Merkez Bankası (Bank of England)}

İngiltere Merkez Bankası, pandemi sürecinde yüz yüze eğitimlerin tamamını durdurduğunu belirtmiştir. Yüz yüze eğitimler yerine sanal sınıf oturumlarının düzenlendiği; çalışanların dışardan alınan dijital öğrenme platformu üzerinden özyönetimli öğrenmeye (self-serve learning) teşvik edildiği ifade edilmiştir. Çevrimiçi eğitimler kapsamında, sanal sınıfların düzenlenmesi için Bankanın video konferans platformu olan Avaya Equinox'un yanında -belirli güvenlik şartlarını sağlamak koşuluylaWebex, Zoom, MSTeams vb. platformlardan da faydalanıldığı iletilmiştir. Ayrıca, çalışanlar için uzaktan çalışma, hibrit toplantılar gibi önemli konularda yazılı kılavuzlar hazırlanmış; görev gereği zorunlu olan eğitimler ve temel yetkinlik eğitimlerine öncelik verilmiştir. Banka çalışanlarının çevrimiçi eğitim faaliyetlerine karşı genel olarak pozitif tutum sergilediği, öğrenme noktasında esneklik sağladığı için sanal eğitimlerden memnun kaldıkları belirtilmiştir. Bununla birlikte, yüz yüze eğitimlerin tamamen dijital ortama taşınması sürecinde teknik sorunlar ve Bankanın güvenlik politikasından kaynaklanan çeşitli kısıtlarla karşılaşıldığı ifade edilmiştir.

\section{Japonya Merkez Bankası (Bank of Japan)}

Japonya Merkez Bankası, pandemi sürecinde gerekli önlemler alınarak sadece merkez ofis çalışanları için yüz yüze eğitimlerin devam ettiğini belirtmiştir. Çevrimiçi eğitimler kapsamında, kurum içinde kullanılan çevrimiçi video konferans sistemi aracılı̆̆ıyla sanal sınıfların gerçekleştirildiği belirtilmiştir. Sanal sınıflarda katılımcılar arasında sosyalleşme (networking) imkânı zor olsa da, bulaş riski azaldığı için çalışanlardan olumlu geri bildirimler alındığı ifade edilmiştir. Pandemi koşulları nedeniyle yeni işe başlayan çalışanların temel eğitimlerini çevrimiçi ortamda almak zorunda kalmaları nedeniyle birbirlerini yüz yüze tanıma imkânı olmadığından, bu çalışanlara yönelik takip programı uygulanmaya başlanmıştır. Pandemi sürecinde eğitim programları arasında önceliklendirme yapıldığı, belirli bir seviyeye terfi eden veya belirli yaşa ulaşan personeli hedefleyen programlara öncelik verildiği belirtilmiştir.

\section{Malezya Merkez Bankası (Bank Negara Malaysia)}

Malezya Merkez Bankası bir kaç eğitim haricinde yüz yüze eğitime ara verildiğini, söz konusu yüz yüze eğitimlerin ise salgın tedbirleri alınmak suretiyle uygulandığını belirtmiştir. Microsoft Teams platformunda sanal sınıflar, çevrimiçi seminerler ve Banka genelinde çoklu katılımlı konuşmalar şeklinde düzenlenen çevrimiçi programların, katılımcılar tarafından olumlu karşılandığı iletilmiştir. Bununla birlikte, tüm eğitim süreçlerinde öğrenilen bilgilerin kalıcılığının tesis edilmesi, yeni öğrenme yöntemine uyumun sağlanması ve paydaşların sanal gerekliliklere yönelik beklentilerinin karşılanması gibi zorluklarla karşılaşıldığı ifade edilmiştir. Bu süreçte sanal ortamda etkin bilgi transferine yönelik düzenlemelerin yapılması gerekliliği belirtilerek, planlı sanal eğitim programlarına ek olarak, çalışanlarının serbest zamanlarında öğrenimlerini desteklemek amacıyla çevrimiçi öğrenme materyallerine istedikleri zaman erişebilme imkânı da sağlanmıştır. Bu dönemde yeni bir eğitim süreci uygulamaya konulmamakla birlikte, eğitim programları sanal ortama uygun şekilde revize edilmiştir. Örneğin, işbirlikçi öğrenme (collaborative leraning) ve oyunlaştırma (gamification) yöntemleriyle dersler daha etkileşimli olacak şekilde tasarlanmıştır. 


\section{Rusya Merkez Bankası (Bank of Russia)}

Rusya Merkez Bankası, yüz yüze eğitimlere salgın tehlikesi azalıncaya kadar ara verdiğini belirtmiştir. Ülkede karantina kısıtlamalarının gevşetilmesi ve yüz yüze eğitimlerin gerçekleştirilmeye başlamasıyla birlikte bütün eğitim ortamlarında salgına yönelik genel tedbirler alınmıştır. Çevrimiçi eğitim programlarının bu dönemde daha çok benimsendiği, yönetici geliştirme programları dâhil olmak üzere normalde yüz yüze gerçekleştirilen eğitimlerin de uzaktan öğrenme yöntemiyle gerçekleştirildiği ifade edilmiştir. Online eğitimlerde Rusya tarafından geliştirilen Webtutor gibi geleneksel programların yanında iMind gibi çevrimiçi seminer programları ile Microsoft Teams ve Cisco Webex Meeting gibi programlar da kullanıımıştır. Uzaktan öğrenme kapsamında mümkün olan bütün formatların (etkileşimli web seminerleri, işbirliği oturumları, beyin fırtınası oturumları vb.) kullanıldığı vurgulanmıştır.

Online eğitimlere beklentinin çok üzerinde bir ilgi ile karşılaştıklarını belirten Rusya Merkez Bankası, çevrimiçi eğitimlerin çalışanların bilgi transferinin yanı sıra psikolojik dayanıklılıklarına da katkı sağladığını ifade etmiştir. Uzaktan öğrenme süreçlerinde yüz yüze eğitimlerle kıyaslandığında teknik altyapı sorunları ile karşılaşılabildiği, bunun yanında bilgi güvenliği ile ilgili gerekliliklerin de bu süreçte kısıtlamalara neden olabildiği belirtilmiştir. Bilgi güvenliği açısından kritik olan içerikler çevrimiçi platformlara dâhil edilmemiştir.

Temel olarak eğitimlerin önceliklendirilmesi ile ilgili bir değişiklik olmasa da, Rusya Merkez Bankası Üniversitesi tarafından çalışanların yeni şartlara uyumunu amaçlayan kısa içerikli "kişisel izolasyon yönetimi" ve "uzaktan takım yönetimi" eğitimleri geliştirilerek Bankanın iç portalına eklenmiştir. Söz konusu portal ayrıca çalışanların uzaktan öğrenme ve serbest zaman aktiviteleri hakkında bilgi edinmelerine, yabancı dillerini (İngilizce) geliştirebilmelerini destekleyen bilgi toplulukları oluşturulmasına imkân sağlamıştır. Bununla birlikte "psikolojik istikrar", "stres yönetimi teknikleri", "öz düzenleme (selfregulation)", "evde çalışma düzeni" gibi konularda eğitim seansları ve video dersleri de düzenlemiştir.

\subsection{COVID-19 Pandemi Sürecinde Yabancı Merkez Bankalarında Performans Yönetim Sistemleri}

Pandemi döneminin performans sistemlerine olan etkisini değerlendirmek üzere iletişime geçilen ABD, Almanya, Avrupa, Fransa, Japonya, Malezya ve Rusya Merkez Bankaları gönderilen soru setlerini cevaplamıştır. İngiltere Merkez Bankasından performans uygulamaları konusunda dönüş alınamamıştır. Belirtilen Merkez Bankalarının performans uygulamaları ve COVID19 pandemi sürecinin bu uygulamalar üzerindeki etkisi Tablo 2'de yer almaktadır.

Tablo 2: COVID-19 Döneminde Dünya Merkez Bankalarında Performans Uygulamalarının Karşılaştırılması

\begin{tabular}{|c|c|c|c|}
\hline Merkez Bankası & $\begin{array}{l}\text { Performans yönetim sistemi } \\
\text { uygulamaları }\end{array}$ & Performans ödüllendirme süreci & $\begin{array}{l}\text { COVID-19 pandemi sürecinde } \\
\text { yapılan değişiklikler }\end{array}$ \\
\hline $\begin{array}{l}\text { Amerika Merkez Bankası } \\
\text { (Federal Reserve Bank) }\end{array}$ & $\begin{array}{l}\text { Yıllık değerlendirme yapılmakta; } \\
\text { kurum hedefleri ve birim } \\
\text { hedefleriyle uyumlu olarak görev } \\
\text { ve yetkinlik bazlı bireysel hedefler } \\
\text { belirlenmektedir. }\end{array}$ & $\begin{array}{l}\text { Salgın koşullarında çalışanlara } \\
\text { ekstra bir ödüllendirme yapııması } \\
\text { değerlendirilmektedir. }\end{array}$ & $\begin{array}{l}\text { Yazılı hedefler daha basit } \\
\text { düzeyde tutulmuş, çalışan- } \\
\text { yönetici arasındaki geribildirim } \\
\text { görüşmelerine ağırık verilmiştir. }\end{array}$ \\
\hline $\begin{array}{l}\text { Almanya Merkez Bankası } \\
\text { (Deutsche Bundesbank) }\end{array}$ & $\begin{array}{l}\text { Göreve başlanılan ilk üç yıl } \\
\text { boyunca yıllık, sonraki yıllarda üç } \\
\text { yılda bir değerlendirme } \\
\text { yapılmakta; göreve dayalı ve } \\
\text { yönetsel yetkinlikler dikkate } \\
\text { alınmaktadır. }\end{array}$ & $\begin{array}{l}\text { Doğrudan maddi bir } \\
\text { ödüllendirme yapılmamakta, } \\
\text { "Ekstra Bonus Ödemesi Sistemi" } \\
\text { uygulanmakta, terfi mekanizması } \\
\text { kullanılmaktadır. }\end{array}$ & $\begin{array}{l}\text { Tüm süreçler ve hedefler aynı } \\
\text { şekilde işletilmiş, sadece fiziksel } \\
\text { süreçler dijital ortama taşınmıştır. }\end{array}$ \\
\hline $\begin{array}{l}\text { Avrupa Merkez Bankası } \\
\text { (European Central Bank) }\end{array}$ & $\begin{array}{l}\text { Yıllık değerlendirme yapılmakta; } \\
\text { görevle ilişkili teknik hedefler, } \\
\text { yetkinlikler ve kişisel gelişim } \\
\text { hedefleri atanmaktadır. }\end{array}$ & Belirtilmemiştir. & $\begin{array}{l}\text { Hedefler değiştirilmeyip sadece } \\
\text { takvimsel güncelleme yapılmıştır. }\end{array}$ \\
\hline $\begin{array}{l}\text { Fransa Merkez Bankası } \\
\text { (Bank of France) }\end{array}$ & $\begin{array}{l}\text { Yıllık değerlendirme yapılmakta; } \\
\text { görev hedefleri ile davranışsal } \\
\text { hedefler belirlenmektedir. }\end{array}$ & Belirtilmemiştir. & $\begin{array}{l}\text { Birey hedeflerinde göreve dayalı } \\
\text { operasyonel kısmın etkisi } \\
\text { azaltılarak davranış tarafı ön } \\
\text { plana çıkarılmıştır. }\end{array}$ \\
\hline $\begin{array}{l}\text { Japonya Merkez Bankası } \\
\text { (Bank of Japan) }\end{array}$ & Belirtilmemiştir. & Belirtilmemiştir. & $\begin{array}{l}\text { Herhangi bir değişiklik } \\
\text { yapılmamıştır. }\end{array}$ \\
\hline $\begin{array}{l}\text { Malezya Merkez Bankası } \\
\text { (Bank Negara Malaysia) }\end{array}$ & $\begin{array}{l}\text { Yıllık değerlendirme yapılmakta; } \\
\text { ana sonuç alanları ve iş hedefleri } \\
\text { belirlenmektedir. }\end{array}$ & Belirtilmemiştir. & $\begin{array}{l}\text { Performans sistemi daha kısıtlı } \\
\text { işletilmiş, hedefler } \\
\text { basitleştirilmiştir. }\end{array}$ \\
\hline $\begin{array}{l}\text { Rusya Merkez Bankası (Bank } \\
\text { of Russia) }\end{array}$ & $\begin{array}{l}\text { Yıllık değerlendirme yapılmakta; } \\
\text { ortak hedefler, kişisel hedefler ve } \\
\text { gözlemlenen hedefler } \\
\text { belirlenmektedir. }\end{array}$ & $\begin{array}{l}\text { Yılık performans primleri ile aylık } \\
\text { prim mekanizması } \\
\text { uygulanmaktadır. }\end{array}$ & $\begin{array}{l}\text { Herhangi bir değişiklik } \\
\text { yapılmamıştır. }\end{array}$ \\
\hline
\end{tabular}




\section{Amerika Merkez Bankası (Federal Reserve Bank)}

Amerika Merkez Bankası, performans sistemini yıllık olarak yürüttüğünü belirtmiştir. Çalışanların bireysel olarak görev bazlı ve yetkinlik bazı iki tür hedeflerinin bulunmakta, bu hedefler kurum hedefleri ve birim hedefleriyle uyumlu olacak şekilde belirlenmektedir. Dış veya iç faktörlerden kaynaklanan değişimlere göre hedeflerde güncelleme de yapılabilmektedir. COVID19 pandemi koşulları sebebiyle oluşan çalışma ortamında ise yazılı hedefler daha basit düzeyde tutularak çalışan-yönetici arasındaki geribildirim görüşmelerine ağırlık verilmiş, performansın yöneticinin yakın takibi sayesinde değerlendirileceği ifade edilmiştir. Belirlenen yazılı hedeflerin, olumsuz koşullar olsa dahi yapılması gereken işlerden seçildiği vurgulanmıştır. Puanlama sisteminde ise güncellemeye gerek duyulmamıştır. Bunlara ek olarak, salgına rağmen yapılması zorunlu olan işlerde çalışanlara ekstra bir ödüllendirme yapılması hususunun da değerlendirildiği belirtilmiştir.

\section{Almanya Merkez Bankası (Deutsche Bundesbank)}

Almanya Merkez Bankasında performans sistemi diğer merkez bankası uygulamalarından ayrışmaktadır. Yeni başlayanlar için göreve başladıkları ilk üç yıl boyunca yıllık olarak değerlendirme yapılırken, takip eden senelerde üç yılda bir performans değerlendirmesi yapılmaktadır. Performans hedeflerinde sayısal şekilde belirlenmiş göreve dayalı hedefler bulunmamaktadır. Çalışanları, göreve dayalı yetkinlik ve yönetsel yetkinliklere göre değerlendirildikleri görülmektedir. Ana alanlar diye belirtilen üç farklı alanda; işin niteliği ve niceliği, çalışma şekli ile yönetsel davranışta çalışanların kendilerinden beklenen davranışları ne kadar gerçekleştirdiklerine göre puanlamaları yapılmaktadır. Bankadaki performans değerlendirmesinin önemli sonuçlarından biri olarak terfi mekanizmasını tetiklenmesine işaret edilmiş, ortalamanın üstünde performans gösterildiğinde terfi havuzuna giriş sağlandığı belirtilmiştir. Performans sistemindeki değerlendirme sonucunda doğrudan maddi bir ödüllendirme yapılmamakta, ödüllendirme süreci her zaman ödeme yapılabilen "Ekstra Bonus Ödemesi Sistemi" aracılığı ile yürütülmektedir. Bu sistem; çalışanın uzun süredir iyi performans gösteriyor olması, çalışma gruplarında ya da projelerde aktif katılım ve katkı gösteriyor olması vb. durumlarda devreye girmektedir. Pandemi süresince de bu sistem aynı şekilde uygulanmaya devam edilmiştir. COVID-19 pandemi sürecinin performans sisteminde yarattığı değişikliğin dijitalleşme yönünde olduğu ifade edilmiştir. Tüm süreçler ve hedefler aynı şekilde işletilmiş ancak fiziksel olan süreçler dijital ortama taşınarak devam edilmiştir. En önemli süreçlerden biri olan yönetici-çalışan arasındaki geribildirim görüşmesi de çevrimiçi şekilde gerçekleştirildiği belirtilmiştir.

\section{Avrupa Merkez Bankası (European Central Bank)}

Avrupa Merkez Bankasında performans sisteminin Eylül'den Eylül'e olmak üzere yıllık olarak yürütüldüğü belirtilmiştir. Bankada, dış kaynak personel hariç tüm çalışanların sisteme dâhil edildiği vurgulanmıştır. Çalışanlara bir üst yöneticileri tarafından görevleriyle ilişkili teknik hedefler, yetkinlikler ve kişisel gelişim hedefleri atandığı ifade edilmiştir. COVID-19 pandemi sürecinde ise takvimlendirilmiş işlere salgın koşullarından dolayı esneklik tanınmış, hedefler değiştirilmeyip sadece takvimler güncellenerek sürece devam edilmiştir. Performans sisteminin, bunun haricinde hiçbir değişiklik yapılmadan yürütüldüğü iletilmiştir.

\section{Fransa Merkez Bankası (Bank of France)}

Fransa Merkez Bankasında performans sisteminin yıllık olarak yürütüldüğü ifade edilmiştir. Çalışanların görev hedefleri ile davranış hedefleri bulunmakta ve sadece bir üst yöneticileri tarafından değerlendirilmektedir. Yönetici, bir önceki yılın değerlendirmesini yaptığı sırada çalışanın yeni dönem hedeflerini de belirlemektedir. Ayrıca, çalışanın geliştirmesi gereken özellikleri ve yeni yılda katılması gereken eğitimler açıkça belirtilmektedir. COVID-19 pandemi süreci kapsamında ise, birey hedeflerinde göreve dayalı operasyonel kısmın etkisini azaltıp davranış tarafının ön plana çıkarılacağına değinilmiştir. Ayrıca, çalışanların bu dönemde gösterdikleri esneklik ve uyum kabiliyetinin de yeni bir hedef olarak değerlendirmeye alındığı belirtilmiştir. Performans puanlaması ve yeni dönem performans hedeflerinin belirlenmesi süreçlerinde bir değişiklik olmadığı iletilmiştir.

\section{Japonya Merkez Bankası (Bank of Japan)}

Japonya Merkez Bankası, COVID-19 pandemi sürecinin performans sistemlerinde hiçbir değişiklik ya da güncellemeye sebep olmadığını belirterek sistemin detaylarına ilişkin bilgi vermemeyi tercih etmiştir.

\section{Malezya Merkez Bankası (Bank Negara Malaysia)}

Malezya Merkez Bankasında performans sisteminin yıllık olarak yürütüldüğü belirtilmiştir. Çalışanlar her yılın başında ana sonuç alanları ve iş hedeflerini belirlemekte, liderlik yetkinlikleri ve teknik yetkinlikler ise kendilerine otomatik atanmaktadır. COVID-19 pandemi süreci sebebiyle performans sisteminin daha kısıtlı işletildiği ve hedeflerin daha basitleştirilmiş şekilde değerlendirileceği ifade edilmiştir.

\section{Rusya Merkez Bankası (Bank of Russia)}

Rusya Merkez Bankasında performans sisteminin yıllık olarak yürütüldüğü ve diğer Merkez Bankalarından farklı olarak, tüm çalışanları değil; sadece yöneticileri ve yüksek kademedeki uzmanları kapsadığı belirtilmiştir. Yönetici-çalışan arasındaki 
toplantıda bir önceki yııın değerlendirmesi yapılırken çalışanın yeni dönem hedefleri de belirlenmektedir. Çalışanlara 3 farklı tipte hedef ataması yapılmaktadır: 1- Üst Yönetim tarafından belirlenen ve herkesin hedef karnesinde yer alan ortak hedefler, 2- Kişisel hedefler (çalışanın görev aldığı işinden kaynaklı) 3- Gözlemlenen hedefler (çalışanın görevi haricinde rol aldığı önemli başka alanlardan kaynaklı). Rusya Merkez Bankası ilgi çekici bir uygulama olarak, yıllık performans primleri haricinde aylık prim mekanizması isminde ekstra bir ödüllendirme yapmaktadır. Kısa vadeli değerlendirme yapılan bu yöntem aracılığı ile; aniden ortaya çıkan önemli işlerin gerçekleştirilmesi, takvimi uzun bir işin kısa sürede yoğun emekle tamamlanması, yaratıcı çözümler üretilmesi, zamanında ve yerinde inisiyatif alınması gibi pek çok farklı olumlu gelişme ödüllendirilmektedir. COVID19 pandemi süreci kaynaklı herhangi bir sebebin performans sistemindeki işleyişi etkilemediği ifade edilmiştir.

\subsection{Türkiye Cumhuriyet Merkez Bankası'nda Eğitim ve Gelişim Faaliyetleri ve COVID-19 Pandemi Süreci}

Türkiye Cumhuriyet Merkez Bankası (TCMB) bünyesinde eğitim ve gelişim faaliyetleri İnsan Kaynakları Genel Müdürlüğü'ne bağlı Merkez Akademi ve Gelişim Müdürlüğü tarafından yürütülmektedir. Müdürlüğün görev tanımında Banka çalışanlarına yönelik mesleki teknik eğitimler, davranışsal gelişim eğitimleri, oryantasyon eğitimleri, yasal zorunlu eğitimler ve yetkinlik geliştirme programları, yurt içi ve yurt dışı eğitimler ve lisansüstü programların düzenlenmesi ve takibi yer almaktadır. Bankaca düzenlenen eğitim programları, ihtiyaç analizi çerçevesinde tasarlanmakta, programın uygulanmasının ardından değerlendirme aşaması ile süreç tamamlanmaktadır. Eğitim teknolojileri kapsamında e-öğrenme materyallerinin temini ile dijital öğrenme alanındaki gelişmelerin takibi gerçekleştirilmektedir. Ayrıca, yabancı merkez bankaları, uluslararası kuruluşlar ve eğitim kuruluşları tarafından düzenlenen eğitim programlarına çalışanların katılımı da sağlanmaktadır.

Dünyayı etkisi altına alan COVID-19 salgını, yabancı Merkez Bankalarında olduğu gibi TCMB'de de neredeyse bütün eğitim süreçlerinin baştan tasarlanmasını gerektirmiş; yeni normale ayak uydurabilmek için çeşitli çalışmalar yapılmıştır. Bu kapsamda, yüz yüze eğitimlerin tamamına yakını askıya alınmıştır. Ertelenmesi mümkün olmayan ve stratejik öneme sahip eğitimler hijyen koşullarına dikkat edilerek sınıf ortamında düzenlenmiştir. Çevrimiçi eğitimlerde Bankaya özgü geliştirilen TCMB-Meeting platformunun yanında Webex, Zoom, MicrosoftTeams platformları da ihtiyaçlar doğrultusunda kullanılmıştır. Ayrıca, farklı e-öğrenme hizmet sağlayıcılarından hizmet temini yapılarak çeşitli teknik ve kişisel gelişim eğitimleri çalışanların erişimine açılmıştır. Çalışanların ücretsiz olarak faydalanabileceği çevrimiçi eğitimleri içeren bir katalog da hazırlanarak çalışanlara sunulmuştur. Bu süreçte, TCMB çalışanlarının çevik bir yaklaşımla sürece hızlıca uyum sağladığı, sunulan çevrimiçi eğitim çözümlerinden büyük bir özen ve istekle faydalandıkları görülmüştür.

\subsection{Türkiye Cumhuriyet Merkez Bankası'nda Performans Yönetim Sistemi ve COVID-19 Pandemi Süreci}

Türkiye Cumhuriyet Merkez Bankası’nda performans yönetimi işlemleri İnsan Kaynakları Genel Müdürlüğü’ne bağlı Strateji ve Performans Yönetimi Müdürlüğü tarafından yürütülmektedir. Illk olarak stratejik plan kapsamındaki önceliklere göre Kuruma ait Temel Performans Göstergeleri (TPG) belirlenmektedir. Kurum TPG'leri; Birim TPG'lerine giden yolu, Birim TPG'leri ise Birey TPG'lerine giden yolu açmaktadır. Performans Yönetim Sistemi'nde nihai nokta olan Birey TPG'leri, hedefler ve yetkinlikler üzerine inşa edilmiştir. Bireylerin TPG listesinde yer alan hedefler 3 farklı tiptedir: Kurum Hedefleri, Fonksiyonel Hedefler (Çalışanın görevinden kaynaklı teknik hedefler) ve Organizasyonel Gelişim Hedefleri (sadece yönetici kademeleri için). Yetkinlikler de 3 farklı tiptedir: Temel Yetkinlikler, Göreve Dayalı Yetkinlikler ve Yönetsel Yetkinlikler (sadece yönetici kademeleri için). Genel olarak yetkinlikler; çalışanın bulunduğu pozisyonda üstlendiği görevleri yüksek performansla yerine getirebilmesi için sahip olması gereken bakış açısı, bilgi ve becerileri yansıtan davranışlardır. Çalışanlar iş birimi bazında ayrışan yetkinlikler ışığında pozisyonlarına bağlı olarak farklı yetkinlikler üzerinden değerlendirilmektedir. Yıllık olarak yürütülen Performans Yönetim Sistemi'nde, değerlendirme dönemi sonunda hedef gerçekleşmeleri tespit edilerek performans puanları hesaplanmaktadır. TPG belirlenmesindeki sıraya benzer olarak öncelikle Kurum performans puanı, sonrasında Birim performans puanları ve nihai olarak Birey performans puanları oluşturulmaktadır.

Bireysel performansın değerlendirilmesi kapsamında, COVID-19 pandemi sürecinde oluşabilecek aksaklıkların giderilmesi ve herhangi bir mağduriyet oluşmaması amacıyla yönetici kademeleri haricindeki tüm çalışanların sadece yetkinlikler çerçevesinde değerlendirilmesi uygun bulunmuştur. Yönetici kademelerindeki çalışanlara ise normal işleyişte olduğu üzere hem hedefler hem de yetkinlikler atanmıştır. Birim performansı kapsamındaki süreç yine normal şekilde uygulanmış, tüm Birimlere ait TPG listeleri oluşturulmuştur. Kurum performans hedefleri ise Üst Yönetim görüşü doğrultusunda 2020 yılında pandemi sürecinden bağımsız olarak belirlenmemiştir. Pandemi koşullarının, TCMB performans değerlendirme sürecine büyük bir değişikliğe neden olmayacağı değerlendirilmiştir.

\section{SONUÇ VE DEĞERLENDIRME}

Merkez bankalarından gelen cevaplar göz önünde bulundurulduğunda COVID-19 döneminde çoğunlukla yüz yüze eğitimlere ara verildiği, eğitimlerin yüz yüze düzenlenmesi halinde salgın tedbirlerinin uygulandığı, genel olarak eğitimlerin uzaktan öğrenme yöntemiyle sürdürülmesinin benimsendiği anlaşılmaktadır. Çevrimiçi eğitim altyapısını oluşturma ve uygulama süreçlerinde zaman zaman aksaklıklarla karşılaşılması, katılımcılar arasında sosyalleşme imkânının zor olması gibi olumsuz yönler belirtilse de, Merkez Bankaları çalışanlarının çevrimiçi eğitimlere karşı olumlu bir tavır sergilediğini ifade etmişlerdir. Teknik altyapı sorunlarının ve bilgi güvenliği politikaları nedeniyle yaşanan kısıtların da ortak yaşanan zorluklar arasında yer 
aldığı görülmektedir. Genel olarak salgın sürecinde eğitim uygulamaları ve bu kapsamda alınan önlemler ile Ülkemiz uygulamalarının benzerlik gösterdiği anlaşılmaktadır.

Eğitim ve gelişim faaliyetleri kapsamında, Fransa Merkez Bankası'nın yöneticiler için sunduğu uzaktan çalışma döneminde kurallar, işi organize etme, riskleri önleme gibi konuları içeren "kriz döneminde uzaktan yönetim" eğitim programı dikkat çekmektedir. Avrupa Merkez Bankasının da benzer bir eğitim programını düzenlemeye yönelik çalışmalar başlattığı görülmektedir. İngiltere Merkez Bankasının çalışanları için uzaktan çalışma ve hibrit toplantılar gibi önemli konularda hazırladığı yazılı kılavuzlar iyi uygulama örnekleri olarak değerlendirilmektedir. Rusya Merkez Bankasının çalışanların yeni şartlara uyumuna yönelik geliştirilen eğitimleri sunabildikleri, uzaktan öğrenme ve serbest zaman aktiviteleri hakkında bilgi edinebilecekleri, yabancı dillerini (İngilizce) geliştirebilmelerini destekleyen bilgi toplulukları oluşturabildikleri eğitim portalı faydalı bir uygulama olarak öne çıkmaktadır. Ayrıca, yaygın kullanılan sanal sınıf eğitimleri ve çevrimiçi seminerlerin yanında oyunlaştırma (gamification) ve işbirlikçi öğrenme (collaborative learning) gibi yeni nesil öğrenme eğilimlerini eğitim intiyaçlarına göre uyarlayabilen Malezya Merkez Bankasının yenilikçi yaklaşımı kurumsal eğitim uygulamalarının geleceği açısından önemli olarak değerlendirilmektedir.

Performans yönetim uygulamaları incelendiğinde ise Ülkemizde olduğu gibi, diğer Merkez Bankalarında da performans sistemi süreçlerinin pandemi koşullarından kısmi olarak etkilendiği ve geçici bazı uygulamalar yapıldığı ancak kalıcı bir sistem değişikliği planlanmadığı gözlemlenmiştir. Bu noktada, Merkez Bankası çalışanlarının çoğunlukla beyaz yakalı çalışanlar olduğu ve iş süreçlerinin önemli bir kısmını dijital ortamlarda uzaktan da etkin bir şekilde yürüttüğü göz önünde bulundurulmalıdır. Fiziksel olarak ofisten uzak olmanın bir takım olumsuzluklara neden olsa da çalışan hedeflerinin gerçekleştirilmesinde ciddi yansımalarının olmadığı değerlendirilebilir.

Sonuç olarak, bu çalışma kapsamında Dünyanın farklı ülkelerindeki Merkez Bankalarının COVID-19 pandemi sürecindeki eğitim ve gelişim faaliyetleri ile performans uygulamaları incelenmiştir. Yüzyılda bir görülebilecek küresel ölçekte bir etkiye sahip olan COVID-19 pandemi süreci tüm kurumlarda olduğu gibi Merkez Bankaları için de ciddi sınama ve zorlukları beraberinde getirmiştir. Çalışmada sunulan farklı ülkelerdeki uygulama örneklerinin, hem tüm Dünyadaki diğer Merkez Bankaları hem de diğer kurumların insan kaynakları yönetim süreçlerinde faydalı olacağı değerlendirilmektedir. İlerleyen dönemlerde pandemi sürecinin çeşitli insan kaynakları uygulamalarına etkilerinin bütünsel olarak incelendiği daha kapsamlı araştırmaların da yapılması önerilmektedir.

\section{KAYNAKÇA}

Aguinis, H., \& Burgi-Tian, J. (2021). Measuring performance during crises and beyond: The Performance Promoter Score. Business Horizons, 64(1), 149-160.

Akkermans, J., Richardson, J., \& Kraimer, M. (2020). The Covid-19 crisis as a career shock: Implications for careers and vocational behavior. Journal of Vocational Behavior, 119, 103324.

Armstrong, A. \& Foley, P. (2003), "Foundations for a learning organization: organization learning mechanisms", The Learning Organization, 10(2), 74-82

Barutçugil, ì. (2002). Eğiticinin eğitimi: Eğitim becerilerinin geliştirilmesi. Kariyer yayıncılık.

Bingöl, D. (2003). Insan Kaynakları Yönetimi, Beta Yayıncılık, İstanbul.

Bozkurt, A. (2020). Koronavirüs (Covid-19) pandemi süreci ve pandemi sonrası dünyada eğitime yönelik değerlendirmeler: Yeni normal ve yeni eğitim paradigması. Açıöğretim Uygulamaları ve Araştırmaları Dergisi, 6(3), 112-142.

Bretz, R. D., Milkovich, G. T. \& Read, W. (1992). The Current State of Performance Appraisal Research and Practice: Concerns, Directions, and Implications. Journal of Management, XVIII, 2, 321-352.

Bui, H. T. (2019). On definitions of the learning organization: toward a new definition of learning organization. The Oxford Handbook of The Learning Organization. Oxford: Oxford University Press, 137-147.

Bulut, C., \& Culha, O. (2010). The effects of organizational training on organizational commitment. International journal of Training and Development, 14(4), 309-322.

Carnevale, J. B., \& Hatak, I. (2020). Employee adjustment and well-being in the era of COVID-19: Implications for human resource management. Journal of Business Research, 116, 183-187.

Davies, I. C. (1999). Evaluation and performance management in government. Evaluation, 5(2), 150-159.

Edmondson, A., \& Moingeon, B. (1998). From organizational learning to the learning organization. Management Learning, 29(1), 5-20.

Fletcher, C. \& Perry, E. L. (2001). Performance Appraisal and Feedback: a Consideration of National Culture and a Review of Contemporary Research and Future Trends. (Editör: N. Anderson, D. S. Önes, H. Kepir-Sinangil, C. Viswesvaran), Handbook of Industrial, Work, and Organizational Psychology, London: Thousand Oaks, New Delhi: Sage Publications, 126-144.

Garvin, D. A., Edmondson, A. C., \& Gino, F. (2008). Is yours a learning organization?. Harvard Business Review, 86(3), 109. 
Groenendaal, J., \& Helsloot, I. (2021). Cyber resilience during the COVID-19 pandemic crisis: A case study. Journal of Contingencies and Crisis Management.

Hartle F. (1995). How to Re-Engineer Your Performance Management Process. Kogan Page Limited, London, $1995,89$.

Herath, T., \& Herath, H. S. (2020). Coping with the new normal imposed by the COVID-19 pandemic: Lessons for technology management and governance. Information Systems Management, 37(4), 277-283.

International Monetary Fund (2017). Monetary Policy and Central Banking. International Monetary Fund Fact Sheet. Erişim adresi https://www.imf.org/en/About/Factsheets/Sheets/2016/08/01/16/20/Monetary-Policy-and-Central-Banking

Kirilmaz, S. K., (2020). Digital transformation in human resources management: investigation of digital hrm practices of businesses. Research Journal of Business and Management (RJBM), V.7(3), 188-200.

Kniffin, K. M., Narayanan, J., Anseel, F., Antonakis, J., Ashford, S. P., Bakker, A. B., ... \& Vugt, M. V. (2021). COVID-19 and the workplace: Implications, issues, and insights for future research and action. American Psychologist, 76(1), 63.

Martin, D. C. \& Bartol, K. M. (1998). Performance Appraisal: Maintaining System Effectiveness. Public Personnel Management, XXVII, 2, 223230 .

Mills, D. Q., \& Friesen, B. (1992). The learning organization. European Management Journal, 10(2), 146-156.

Nutsubidze,N. \& , Schmidt, D.A. (2021). Rethinking the role of HRM during COVID-19 pandemic era: Case of Kuwait. Review of Socio-Economic Perspectives, Vol 6(1), 1-12.

Olaniyan, D. A., \& Ojo, L. B. (2008). Staff training and development: A vital tool for organizational effectiveness. European journal of Scientific Research, 24(3), 326-331.

Serifsoy, A., \& Teker, S. (2020). Adaptation of the businesses not to fall behind in the new normal period. PressAcademia Procedia, 11(1), 163-167.

Tannenbaum, S. I., \& Yukl, G. (1992). Training and development in work organizations. Annual Review of Psychology, 43(1), 399-441.

Tuna, A. A., \& Çelen, O. (2020). İşletmelerin insan kaynakları yönetimi uygulamaları üzerinde COVID-19 pandemisinin etkileri. OPUS Uluslararası Toplum Araştırmaları Dergisi, 16(30), 2710-2759.

Türkiye Cumhuriyet Merkez Bankası (2018). 100 Soruda Merkez Bankacılığı Erişim adresi https://www.tcmb.gov.tr/wps/wcm/connect/2d9f2c1d-18eb-4124-8fd9-

a4ea189a24ad/100+Soruda+TCMB+web.pdf?MOD=AJPERES\&CACHEID=ROOTWORKSPACE-2d9f2c1d-18eb-4124-8fd9-a4ea189a24admR8fxaz

Vnoučková, L. (2020). Impact of COVID-19 on human resource management. Revista Latinoamericana de Investigación Social, 3(1), $18-21$.

Yang, B., Watkins, K. E., \& Marsick, V. J. (2004). The construct of the learning organization: Dimensions, measurement, and validation. Human Resource Development Quarterly, 15(1), 31-55.

Zhao, Y. (2020). COVID-19 as a Catalyst for Educational Change. Prospects, 49(1), 29-33. 